\title{
Comparison of Pasteur and Behringwerke antivenoms in envenoming by the carpet viper (Echis carinatus)
}

\author{
D A WARRELL, M J WARRELL, W EDGAR, C R M PRENTICE, JERRELL MATHISON, \\ JOYCE MATHISON
}

\section{Summary and conclusions}

Bites and envenoming by the carpet viper Echis carinatus are common medical emergencies in parts of Nigeria, but the most effective use of the various commercially produced antivenoms in treatment has not been established. Pasteur Paris Echis monospecific and Behringwerke West and North Africa Bitis-Echis-Naja polyspecific antivenoms were compared in two groups of seven patients with incoagulable blood after $E$ carinatus bites. In both groups spontaneous bleeding stopped within a few hours and local swelling subsided within two weeks after the initial antivenom injection. Pasteur antivenom $(20-40 \mathrm{ml})$ restored blood coagulability within 12 hours in all cases, but $60-180 \mathrm{ml}$ of Behringwerke antivenom was effective in only four cases. Persisting venom procoagulant activity was observed in the remaining three cases.

Despite its potency in the mouse protection test, Behringwerke antivenom is unreliable and unpredictable in neutralising venom procoagulant in humans bitten by E carinatus.

\section{Introduction}

The saw-scaled or carpet viper (Echis carinatus) is the most important cause of mortality and morbidity from snake bite throughout areas of West and North Africa, the Middle East, and India. ${ }^{1} E$ carinatus venom (ECV) may cause local swelling, blistering, and necrosis of the bitten limb. The most important systemic effects are defibrination, owing to a powerful procoagulant that activates prothrombin directly, and spontaneous haemorrhage resulting from vessel-wall damage. ${ }^{2}$ Clinical trials have established the effectiveness of South African Institute for Medical Research (SAIMR) Echis antivenom against systemic and possibly local actions of the venom. ${ }^{34}$ Unfortunately, for political reasons, SAIMR antivenom may no longer be imported to West Africa. In this region the two principal commercially available antivenoms with specific activity against ECV are Behringwerke North and West Africa (Bitis-Echis-Naja) polyspecific and Pasteur Paris Echis monospecific antivenoms. The Behringwerke antivenom has not proved consistently effective. ${ }^{2} 3$

Nuffield Department of Clinical Medicine and Department of Virology, John Radcliffe Hospital, Headington, Oxford OX3 9DU

D A WARRELL, DM, FRCP, consultant physician (present appointment: consultant, faculty of tropical medicine, Mahidol University, Bangkok 4 Thailand)

M J WARRELL, MRCP, MRCPATH, senior registrar (present appointment: consultant, faculty of tropical medicine, Mahidol University, Bangkok 4, Thailand)

University Department of Medicine, Royal Infirmary, Glasgow

W EDGAR, BSC, senior biochemist (present appointment: research scientist, Wellcome Research Laboratories, Beckenham, Kent)

C R M PRENTICE, MD, FRCP, reader in medicine

Bambur General Hospital, c/o Sudan United Mission (United Methodist Branch), PO Box 659, Jos, Nigeria

JERRELL MATHISON, MD, medical officer

JOYCE MATHISON, MD, medical officer
In 1975 two of us began to achieve good results with the Pasteur Echis antivenom at Bambur General Hospital, which admits over 100 cases of Echis bite each year. This study is a formal comparison of these two antivenoms.

\section{Patients and methods}

Patients-Fourteen patients with snake bites admitted to Bambur General Hospital in May and June 1977 were found to have incoagulable blood, which in West Africa is diagnostic of envenoming by $E$ carinatus. ${ }^{2}$ In six cases the dead snake was brought in and found to be $E$ carinatus ocellatus Stemmler; the average length was $60 \mathrm{~cm}$ (these specimens were deposited at the British Museum, Natural History (accession numbers 1979 31-6)). Patients were randomly allocated to receive either Behringwerke or Pasteur antivenom.

Assessment-Symptoms and signs were recorded on standard forms, and local swelling was measured as described. ${ }^{3} \mathrm{~A}$ simple whole-blood clotting test was repeated at six-hourly intervals after antivenom treatment until coagulability had been restored. It was then repeated daily until the patient was discharged after about one week. Clot quality was assessed by the method of Reid $e t a l,{ }^{5}$ packed cell volume measured, and platelets counted. Blood samples taken on admission and six, 24, and 48 hours later and on discharge were centrifuged to provide citrated plasma or serum and then frozen. Concentrations of the following were subsequently measured by methods described elsewhere ${ }^{3}$ : fibrinogen; clotting factors II, X, and XIII; and fibrinand fibrinogen-related degradation products (FDP).

Treatment-Patients given the Behringwerke antivenom received an initial dose of $60 \mathrm{ml}$ (batch No 386, expiry 19 November 1978), and those given the Pasteur antivenom received $20 \mathrm{ml}$ (lot No 10 1257A, expiry 28 June 1977). Undiluted antivenom was injected intravenously over a minimum of 10 minutes. The doses were repeated if blood sampled six hours later or subsequently failed to clot.

Detection of venom procoagulant-In three patients whose clot quality failed to return to normal after they had received antivenom, circulating venom procoagulant activity was measured. Blood was taken into tubes containing either citrate or citrate plus $1 \%$ volume SAIMR Echis antivenom. The plasma was incubated at $37^{\circ} \mathrm{C}$ with an equal volume of normal platelet-poor plasma and was examined for evidence of clotting at hourly intervals up to 24 hours. A clot in the tube containing no antivenom indicated that circulating venom procoagulant was still present in the sample. In the tubes containing antivenom no clots were seen within 72 hours.

Statistical analysis-Non-parametric variables such as clot quality (graded 1 to 5), FDP concentration (method could not distinguish between values over $1280 \mathrm{mg} / \mathrm{l}$ ), and fibrinogen concentration (method could not distinguish between values under $0.15 \mathrm{~g} / \mathrm{l}$ ) were analysed by Wilcoxon's rank sum test.

\section{Results}

Comparability of groups before antivenom was given (tables I and II, fig 1)-The two groups were comparable in all respects save serum FDP concentration, which was significantly higher in the Pasteur group ( $\mathrm{p}<0.05)$.

Response to antivenom (table III)-All patients recovered completely. Local effects of envenoming resolved similarly in the two groups: swelling had virtually disappeared and normal function was restored in the bitten limb one to two weeks after admission. One patient developed local blistering, but none developed necrosis.

Spontaneous bleeding-Bleeding was detected in nine patients. The sites were gingival sulci (eight patients); renal tract (four); nose (two); and old wounds, middle ear, respiratory tract, floor of mouth, and uterus (one each). Bleeding from observable sites such as the gingival 
TABLE I-Comparison of groups before antivenom treatment

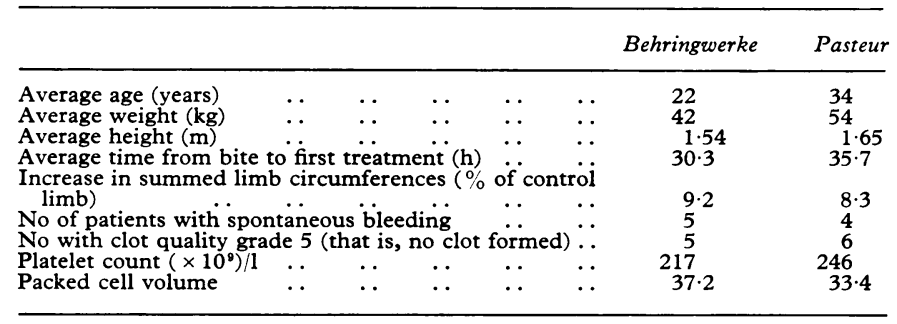

TABLE II-Mean concentrations $( \pm 1 S E)$ of clotting factors $(U / d l)^{*}$ in the two groups

\begin{tabular}{|c|c|c|c|c|c|}
\hline \multirow{2}{*}{$\begin{array}{l}\text { Treatment } \\
\text { group }\end{array}$} & \multirow{2}{*}{$\begin{array}{c}\text { Before } \\
\text { treatment }\end{array}$} & \multicolumn{3}{|c|}{$\begin{array}{l}\text { Hours after initial dose } \\
\text { of antivenum }\end{array}$} & \multirow{2}{*}{$\begin{array}{l}\text { On } \\
\text { discharge }\end{array}$} \\
\hline & & 6 & 24 & 48 & \\
\hline \multicolumn{6}{|c|}{ Factor $I I$} \\
\hline $\begin{array}{l}\text { Behringwerke } \\
\text { Pasteur } \\
\text { Significance }\end{array}$ & $\begin{array}{l}24 \pm 13 \\
64 \pm 17\end{array}$ & $\begin{array}{l}32 \pm 6 \\
80 \pm 14 \\
p<0.025\end{array}$ & $\begin{array}{c}54 \pm 5 \\
89 \pm 14 \\
\mathrm{p}<0.05\end{array}$ & $\begin{array}{c}66 \pm 15 \\
109 \pm 6 \\
p<0.05\end{array}$ & $\begin{array}{l}68 \pm 10 \\
60 \pm 22\end{array}$ \\
\hline \multicolumn{6}{|c|}{ Factor $X$} \\
\hline $\begin{array}{l}\text { Behringwerke } \\
\text { Pasteur }\end{array}$ & $\begin{array}{l}76 \pm 23 \\
62 \pm 19\end{array}$ & $\begin{array}{l}58 \pm 12 \\
72 \pm 18\end{array}$ & $\begin{array}{r}77 \pm 16 \\
102 \pm 12\end{array}$ & $\begin{array}{l}80 \pm 13 \\
95 \pm 13\end{array}$ & $\begin{array}{l}79 \pm 14 \\
83 \pm 15\end{array}$ \\
\hline \multicolumn{6}{|c|}{ Factor XIII } \\
\hline $\begin{array}{l}\text { Behringwerke } \\
\text { Pasteur } \\
\text { Significance }\end{array}$ & $\begin{array}{l}27 \pm 15 \\
32 \pm 12\end{array}$ & $\begin{array}{l}30 \pm 5 \\
40 \pm 13\end{array}$ & $\begin{array}{l}20 \pm 3 \\
69 \pm 19 \\
\mathrm{p}<0.025\end{array}$ & $\begin{array}{l}35 \pm 14 \\
65 \pm 17\end{array}$ & $\begin{array}{l}46 \pm 27 \\
71 \pm 29\end{array}$ \\
\hline
\end{tabular}

*By reference to dilutions of a control sample containing pooled plasma from 15 healthy normal Nigerians in Bambur.
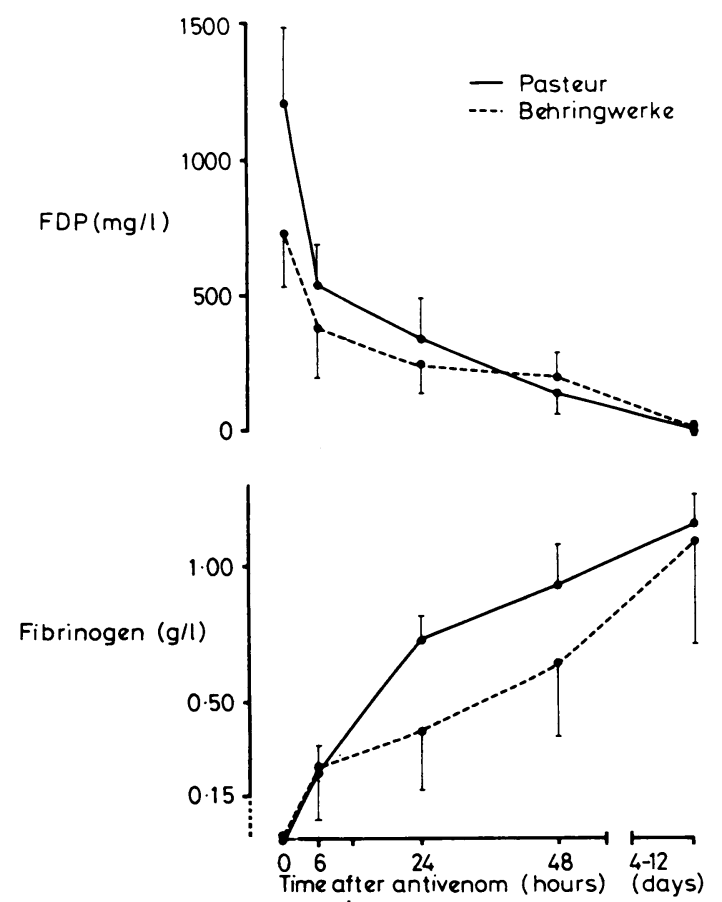

FIG 1-Effect of antivenoms on FDP and fibrinogen concentrations. Mean values (and SE) given.

sulci invariably stopped within a few hours after the first dose of antivenom. The fall in packed cell volume was not significantly different between the two groups. One patient in each group received transfusions of one unit of whole fresh blood when their packed cell volumes fell to 20.5 and $14 \%$.

Coagulation defect-In the Pasteur group, five patients required only the initial $20 \mathrm{ml}$ dose of antivenom to restore permanently blood coagulability as judged by the whole-blood clotting test (fig 2), while two required a second $20 \mathrm{ml}$ dose six hours after the first. In the Behringwerke group the initial $60 \mathrm{ml}$ dose of antivenom permanently restored blood coagulability and normal clot quality in only three

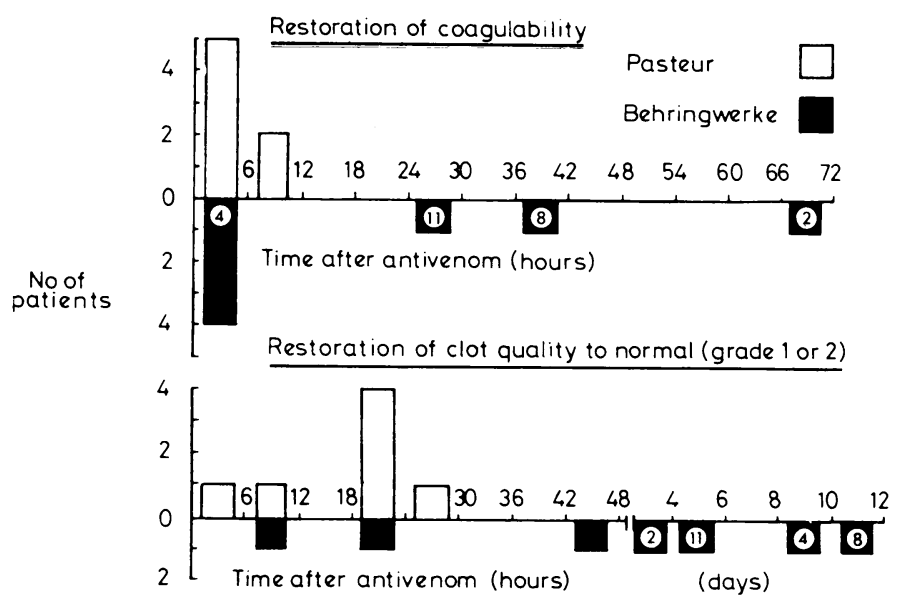

FIG 2-Effect of antivenoms on blood coagulability and clot quality. The four patients in the Behringwerke group with prolonged coagulation disturbance are identified by their case numbers.

TABLE III-Response to antivenom in each group

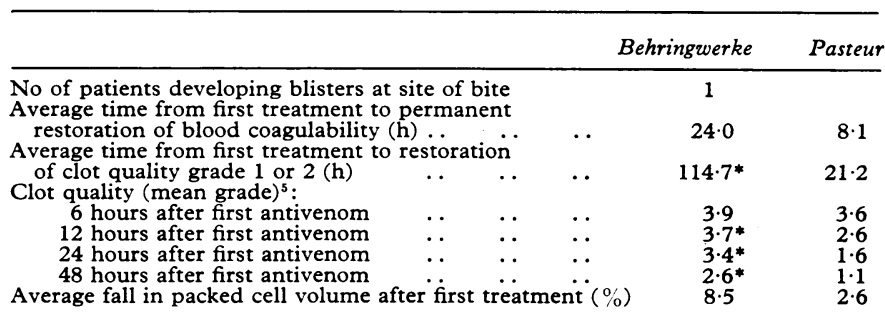

Significance of difference between groups: ${ }^{*} \mathrm{p}<0.05$.

patients. Another patient required two further $60 \mathrm{ml}$ doses, given 24 and 60 hours after the first. In the remaining three patients, although blood coagulability was restored by the initial $60 \mathrm{ml}$ dose (one patient) and by a single additional $60 \mathrm{ml}$ dose given 24 hours (one) and 36 hours (one) later, there was evidence of continuing defibrination: clot quality remained low at grade 4, plasma fibrinogen concentrations remained $<0 \cdot 15 \mathrm{~g} / \mathrm{l}$, factor II concentrations $<50 \mathrm{U} / \mathrm{dl}$, factor XIII $<25 \%$ normal, and FDP within the range $80-1280 \mathrm{mg} / \mathrm{l}$. Venom procoagulant activity was detected in the plasma of these patients but was finally abolished when they were given $20 \mathrm{ml}$ of SAIMR Echis antivenom (table IV). Figure 1 and tables II and III compare blood

TABLE IV-Detection of venom procoagulant activity in patients treated with Behringwerke antivenom

\begin{tabular}{|c|c|c|c|}
\hline \multirow{2}{*}{ Case No } & \multirow{2}{*}{$\begin{array}{l}\text { Days after } \\
\text { initial antivenom given }\end{array}$} & \multicolumn{2}{|c|}{ Clotting time (h) } \\
\hline & & Without antivenom & With antivenom \\
\hline 4 & $\left\{\begin{array}{l}9^{9 *} \\
9 \\
10^{*} \\
11\end{array}\right.$ & $\begin{array}{r}24 \\
3 \\
2 \\
<3 \\
>72\end{array}$ & $\begin{array}{l}>72 \\
>72 \\
>72 \\
>72 \\
>72\end{array}$ \\
\hline 11 & $\left\{\begin{array}{l}4 \\
5^{*} \\
6\end{array}\right.$ & $\begin{array}{r}5 \\
<\quad 4 \\
>72\end{array}$ & $\begin{array}{l}>72 \\
>72 \\
>72\end{array}$ \\
\hline
\end{tabular}

*SAIMR antivenom $(20 \mathrm{ml})$ given to patient after this sample taken

coagulation data for the two groups. The mean concentration of factor II was lower in the Behringwerke group before treatment, but this difference between groups achieved significance only after antivenom was given (table II). Factor XIII concentration was significantly lower in the Behringwerke group 24 hours after antivenom was given. The interval between initial treatment and restoration of normal clot quality was significantly shorter in the Pasteur group $(p<0.05)$ Clot qualities were superior in the Pasteur group at 12 hours $(p<0.05)$, 24 hours $(p<0.02)$, and 48 hours $(p<0.01)$.

Antivenom reactions-Two early reactions to Behringwerke anti- 
venom occurred. One patient became flushed and vomited four minutes after the start of injection, while another developed abdominal colic, itching, vomiting, tachycardia, and sweating after eight minutes. One reaction to Pasteur antivenom occurred: the patient developed mild urticaria 38 minutes after starting treatment. All three reactions were rapidly controlled with subcutaneous adrenaline, $0.5 \mathrm{ml}$ of 1 in 1000. No patient developed later reactions.

\section{Discussion}

We compared initial doses of $60 \mathrm{ml}$ Behringwerke and $20 \mathrm{ml}$ Pasteur antivenoms partly because we expected a monospecific antivenom to have three times the specific activity of a trispecific one, and partly because of clinical experience with the two antivenoms. In a previous study $40 \mathrm{ml}$ of Behringwerke antivenom proved effective in only 55 out of 65 patients, ${ }^{2}$ and we thought it important to test the effects of a higher incremental dose as recommended by the manufacturers." We injected undiluted antivenom intravenously, as this is the most practicable method for the rural tropics. ${ }^{2}$ Slow infusion of diluted antivenom is the method of choice, to minimise early reactions. ${ }^{8}$ The manufacturers of Pasteur antivenom recommend that it be given by intramuscular or subcutaneous injection, ${ }^{9}$ but the effective dose by this route is about 20-30 times greater than that by intravenous injection. ${ }^{10} 11$

The results of this study suggest that $20-40 \mathrm{ml}$ of Pasteur antivenom would be effective in most cases of $E$ carinatus envenoming. This antivenom was less impressive, however, than SAIMR Echis antivenom, which restored normal blood clotting within six hours in 45 out of 48 patients given a dose of $10-20 \mathrm{ml} .^{2}$ Behringwerke antivenom proved disappointing in correcting the coagulopathy, as in past studies. ${ }^{2312}$ In three patients procoagulant activity, which could be neutralised by antivenom in vitro, was detected five to 10 days after treatment with up to $120 \mathrm{ml}$ of Behringwerke antivenom (table IV). The Behringwerke group showed significantly lower concentrations of clotting factors II and XIII up to 48 and 24 hours after treatment respectively (table II), which suggests continuing activation of prothrombin with thrombin formation. Evidently the antivenom had failed to neutralise this venom factor. Thus persisting venom activity rather than "spontaneous" defibrination or an anticoagulant action of the antivenom probably causes the prolonged incoagulable state that has frustrated clinicians using Behringwerke antivenom. ${ }^{3} 12$

In contrast with its clinical performance, Behringwerke antivenom proved more effective than Pasteur antivenom in the mouse protection test, in which survival at 24 hours is usually taken as the end point. ${ }^{13}$ Behringwerke polyspecific antivenom (batch B 207018; $10 \mathrm{ml}$ ) neutralised $154 \mathrm{mg}$ of ECV, whereas the same volume of Pasteur monospecific antivenom (batch 10 1257A) neutralised only $93 \mathrm{mg}$ of ECV (R D G Theakston, personal communication). This disparity is not really surprising, for the venom component that kills a mouse within 24 hours may not be the most important in causing morbidity and mortality in human victims.

The antigenic constituents of snake venoms vary within species, geographically, and even locally. ${ }^{14} 15$ But the venom used to prepare all three antivenoms considered here was obtained in Ethiopia, most probably from the subspecies $E$ carinatus pyramidum (Geoffroy Saint-Hilaire). So geographical differences in venom are unlikely to have caused the observed differences in clinical potency.

In view of the high incidence of $E$ carinatus bites in West Africa manufacturers must be encouraged to improve the clinical effectiveness of their antivenoms for this region. A more potent $E$ carinatus monospecific antivenom is needed. In the past polyspecific antivenoms were preferred because of difficulties in diagnosing the species. But in the particular case of $E$ carinatus bite in West Africa non-clotting blood is evidence both that the snake was indeed $E$ carinatus and that serious systemic envenoming has occurred.
We are grateful to the Ministry of Health, Gongola State, for permission to carry out the study; to the staffs of Bambur General Hospital (formerly Guinter Memorial Hospital), the Sudan United Mission (United Methodist Branch), Jos, and the department of medicine, Ahmadu Bello University Teaching Hospital, Zaria, for their help; to Professor EHO Parry for his encouragement; and to the Wellcome Trust for financial support.

Address for correspondence: Dr D A Warrell, Faculty of Tropical Medicine, Mahidol University, 420/6, Rajvithi Road, Bangkok 4 Thailand.

\section{References}

1 Warrell DA, Arnett C. The importance of bites by the saw-scaled or carpet viper (Echis carinatus). Epidemiological studies in Nigeria and a review of the world literature. Acta Trop (Basel) 1976;33:307-41.

2 Warrell DA, Davidson NMcD, Greenwood BM, et al. Poisoning by bites of the saw-scaled or carpet viper (Echis carinatus) in Nigeria. $Q \mathcal{F} M e d$ $1977 ; 46: 33-62$.

3 Warrell DA, Davidson NMcD, Ormerod LD, et al. Bites by the saw-scaled or carpet viper (Echis carinatus): trial of two specific antivenoms. Br Med $\mathcal{F} 1974$;iv:437-40.

4 Warrell DA, Pope HM, Prentice CRM. Disseminated intravascular coagulation caused by the carpet viper (Echis carinatus): trial of heparin. Br F Haematol $1976 ; 33: 335-42$.

${ }^{5}$ Reid HA, Chan KE, Thean PC. Prolonged coagulation defect (defibrination syndrome) in Malayan viper bite. Lancet 1963;i:621-6.

6 Warrell DA, Greenwood BM, Davidson NMcD, Ormerod LD, Prentice CRM. Necrosis, haemorrhage and complement depletion following bites by the spitting cobra (Naja nigricollis). Qf Med 1976;45:1-22.

7 Behringwerke Aktiengesellschaft. Pamphlet 55. Marburg, 1974.

${ }^{8}$ Sutherland SK. Serum reactions: an analysis of commercial antivenoms and the possible role of anticomplementary activity in de-novo reactions to antivenoms and antitoxins. Med F Aust 1977;1:613-5.

9 Institut Pasteur. Pamphlet 574722. Paris: Institut Pasteur, 1969.

${ }^{10}$ Martin CJ. Further observations concerning the relation of the toxin and anti-toxin of snake-venom. Proc Roy Soc Lond 1898;64:88-94.

11 Christensen PA. The treatment of snake bite. S Afr Med F 1969;43:1253-8.

12 Swinson C. Control of antivenom treatment in Echis carinatus (carpet viper) poisoning. $\operatorname{Tr} R$ Soc Trop Med Hyg 1976;70:85-7.

13 World Health Organisation. Requirements for snake antivenins. WHO Tech Rep Ser $1971 ; 463: 27-44$.

14 Kórnalik F, Táborská E. Individual interspecies variability in the composition of some viperidae venoms. In: Kaiser E, ed. Animal and plant toxins. Munich: Wilhelm Goldmann, 1973:99-103.

${ }^{15}$ Latifi $\mathrm{M}$. Commercial production of anti-snake bite serum (antivenin). In: Gans C, Gans KA, eds. Biology of the reptilia. London: Academic Press, 1978:561-88.

(Accepted 29 November 1979)

ONE HUNDRED YEARS AGO The following preparation of cod-liver oil has been so productive of good effects in my practice, that it leads me to bring it under general notice, with a hope that its use may have a more extended sphere of experiment. The formula and mode of preparation are thus. A. Whisk the yelk and white of an egg in a mortar; gradually add four ounces of light cod-liver oil; mix these ingredients to an uniform consistency; then add half an ounce of dilute phosphoric acid. B. With two ounces of brandy mix a drachm and a half of aromatic spirit of ammonia, and also one drachm each of oil of lemon and oil of almond. Combine A and B, adding brandy to eight ounces. The dose for an adult is two tablespoonfuls two or three times a day; for children, a proportionate quantity. A variation in the essential oils is useful where it is necessary to prescribe the mixture for a lengthened period. The flavour can be altered ad gustandum.

The preparation specially recommends itself for children, who, as my experience has shown, almost invariably take it without compunction, the "medicine-time" being by some looked forward to with pleasure. It appears to be of great value in the pre-tubercular stage of phthisis. The three ounces daily are in most cases taken without causing any deleterious effect on the alimentary canal. The alcohol materially assists the stomach in digesting the oil, when it would otherwise be unable to do so. With children, the use of sherry is sometimes preferable, as the quantity of brandy prescribed might cause unseeming hilarity. FrederIC Young LIVY. (British Medical fournal, 1880.) 